\title{
Growth Hormone Receptors in the Brain and their Potential as Therapeutic Targets in Central Nervous System Disorders
}

\author{
Mathias Hallberg* and Fred Nyberg
}

\author{
Department of Pharmaceutical Biosciences, Division of Biological Research on Drug Dependence, Uppsala University, \\ Sweden
}

\begin{abstract}
Effects that growth hormone (GH) may exert on brain function have received attention among many researchers over the past two decades. In patients with impaired pituitary production of this hormone replacement therapies have been demonstrated not only to compensate for GH effects in peripheral organs but also to improve several behaviors related to the brain. For instance, available data suggests that subjects treated with GH have experienced significant improvements in concentration, memory, depression, anxiety and fatigue. Also, pituitary-ectomized male rats showing decreased ability in tasks related to learning and memory are seen to improve their performance in these items following GH replacement. The mechanism underlying these beneficial effects of GH has been the subject of studies in many laboratories. An important aspect in this regard is the discovery of specific receptors in various brain regions related to the functional anatomy of several behaviors affected by the hormone. The aim with this article is to review current knowledge on GH receptors in the brain and discuss possible mechanism for the action of the hormone in its ability to affects brain function.
\end{abstract}

Keywords: Growth hormone, growth hormone receptor, central nervous system (CNS), learning and memory, blood-brain barrier.

\section{INTRODUCTION}

Since its identification and isolation from pituitary glands growth hormone $(\mathrm{GH})$ have been one of the most extensively studied biological compounds both in the area of basic and clinical science. Pioneer researchers in this regard are Herbert MacLean Evans and Choh Hao Li who have identified, isolated and examined the hormone in various species. The observation that GH may exert effects on the brain comes from physiological studies in experimental animals indicating that the hormone may affect the levels of biogenic amines like noradrenaline, dopamine and serotonin in the hypothalamus [1]. It was later shown that that rat GH may inhibit its own secretion partly via reduction of dopamine and noradrenaline synthesis and release in the hypothalamic median eminence suggested to induce a reduced secretion of $\mathrm{GH}$ releasing factors [2]. These discoveries combined with observations, made in humans subjected to GH replacement therapy, indicating that the hormone may influence a variety of CNS functions in GH deficient (GHD) patients encourage the search for specific $\mathrm{GH}$ targets in the brain. In this line of research it became evident that GH may be produced in extra-pituitary areas of the brain [3].

Furthermore, GH and its mediator insulin-like growth factor I (IGF-I) are expressed in specific regions of the central nervous system (CNS) during early human

\footnotetext{
*Address correspondence to this author at the Department of Pharmaceutical Biosciences, Division of Biological Research on Drug Dependence, Uppsala University, P.O. Box 591, SE-751 24 UPPSALA, Sweden; Tel: +46-18-471-4141; E-mail: Mathias.Hallberg@farmbio.uu.se
}

development [4]. These regions include the hippocampus, pituitary and hypothalamus. It is thus reasonable to believe that the somatotrophic axis (GH/IGF-1) may influence several aspects of behaviors, including cognition, emotion and perception as well as other adjustments that occur from childhood to adulthood. In a study demonstrating that GH is endogenously produced in the adult hippocampal formation it was shown that the secretion of the hormone was regulated by age, estrogen, and exposure to stress [3]. It was further suggested that GH may be involved in processes associated to the hippocampal function, such as learning and the response to stressful experience. A particular aspect in relation to this is the discovery of specific receptors for $\mathrm{GH}$ in the human as well as in the rat hippocampus [5-9].

The presence of $\mathrm{GH}$ receptors in the CNS have been confirmed by binding studies as well as molecular cloning (for review see $[7,10]$ ). High densities of GH binding are detected in the choroid plexus, hypothalamus, pituitary and hippocampus $[5,6]$ and the expression of GHR gene transcripts follow the distribution of the hormone binding. The abundant expression of $\mathrm{GH}$ receptors within the hippocampal and perihippocampal areas has received attention since these structures are primarily involved in declarative memory for facts and events [4]. GHR is also seen to be located in brain regions, e.g. the putamen [5], known for their role in the processing of social perceptions. CNS receptors for IGF-I have been detected in the many areas overlapping those for GH, e.g. amygdala and prefrontal cortex, which are regions with high impacton neural circuits involved in social behavior. Attempts to find relevant approaches for evaluating emotional, social and behavioral 
adjustment among individuals with deficiencies in the GH/IGF-I axis search for instrumentations for objective assessment of their social-cognitive competence [4]. In experimental animals, behavioral tests have been used to assess the impact of the somatotrophic axis on social function and cognitive deficiencies by probing the expression of GHR in both hippocampus and prefrontal cortex [73].

It thus seems that the GH/IGF-I axis may have a distinct role in cognitive function. This hypothesis is supported by many observations made at various clinics but also in many basic research laboratories. As described in other chapters of this volume the two hormones have been extensively studied both in clinics and basic research laboratories regarding their involvement in learning and memory. Clinical work has confirmed that GHD patients display cognitive disabilities $[11,12]$ and experimental animal with impaired GH/IGF-I axis exhibit a deteriorated performance in memory tests [13]. The exact mechanism by which the GH/IGF1 axis influences the cognitive functions is still not clarified. However, studies in experimental rat have revealed a link between the hippocampal expression of GHR and the NMDA receptor complex suggesting a possible GH effect on long term potentiation (LTP) [8, 13]. A further step in the evaluation of this mechanism will certainly involve studies on the function of GH and GHR in the CNS. However, it is also important to consider that central effects of exogenous GH mediated through GHRs in the brain require an ability of the hormone to cross the blood-brain barrier (BBB). Therefore, this article starts to discuss evidence that the hormone may penetrate the $\mathrm{BBB}$ before it reaches its responsive areas in the CNS.

\section{EVIDENCE THAT GH MAY CROSS THE BLOOD- BRAIN BARRIER}

Human GH is represented by a single polypeptide chain of 191 amino acids corresponding to a molecular weight of approximately 22 kdalton. Such molecular size should hardly allow the hormone to penetrate the BBB but still there are several lines of evidence that support the speculation that it may cross the barrier. First, a number of studies carried out at separate clinics have shown that in patients subjected to GH replacement therapy significant effects of the hormone on the mental health can be seen. These effects include improved cognition, increased motivation and increased wellbeing. In adolescents with childhood onset of GHD improved perception and attention have been seen following GH therapy [14]. A second evidence is that $\mathrm{GH}$ has been demonstrated to affect the cerebrospinal fluid (CSF) levels of various neuropeptides, amino acids and monoamine metabolites [15-17]. Furthermore, studies have indicated that the hormone can be recovered from CSF following peripheral administration [18]. Interestingly, Burman and coworkers reported a positive correlation between the dose of exogenous GH and the levels of the hormone recorded in the CSF [19]. It is also noteworthy that the level of both the GH mediator IGF-1 and its binding protein IGFB3 were seen to increase in CSF following GH replacement [16].

As mentioned above, all beneficial effects on mental function seen for GH during replacement therapy suggest that the hormone may find its way from the circulatory system into the CNS [20-22]. Regarding the potential mechanisms for $\mathrm{GH}$ to be transported across the $\mathrm{BBB}$ several routes have been suggested. For instance, GH can reach its responsive sites in the brain by circumventing the BBB through the median eminence of the hypothalamus. The median eminence is known to serve as a circumventricular organ that permits hypothalamic polypeptides to leave the brain without disrupting the BBB. It also allows hormone compounds that do not cross the BBB to interact with brain circuits [23]. Moreover, in conformity with prolactin [24], GH has been suggested to reach the brain via choroid plexus and CSF through a receptor-mediated mechanism $[18,25]$. The choroid plexus is a vascularized tissue with high density of both prolactin and GH binding sites [7, 26]. GH may also actively or passively cross the brain parenchyma capillaries through the BBB $[10,27]$. A recent study suggests that the hormone may significantly diffuse into the CNS [28].

\section{DISTRIBUTION OF GH RECEPTORS IN THE CNS}

The first observation that GH may bind to specific sites in the brain comes from studies focused on lactogenic sites in the rat choroid plexus [29]. This study was followed up by others and in 1991 specific sites for the hormone in human choroid plexus were identified and characterized [25]. This work was followed by studies screening the distribution of GH binding in the rat brain applying autoradiography [30, 31] and classical receptor binding [6]. All these binding techniques revealed that GHR are widely distributed within several areas of both the rat and human brain. Moreover, these studies also revealed sex differences in GH binding both in rat [6, 30] as well as in human [5]. However, it appeared that these sex differences mainly referred to lactogenic binding sites as human $\mathrm{GH}$ (hGH) also has affinity for lactogenic receptors. In the presence of excessive unlabelled prolactin the sex difference seen in hGH binding was abolished [5, 26]. Regarding GH binding the highest density was found in choroid plexus. High levels of GH binding sites were also detected in the hippocampus, hypothalamus, thalamus, putamen and the pituitary [5-7, 10]. Applying in situ hybridization it was found that the GH receptor gene transcript was detected in similar areas [32, 33]. It was further reported that somatostatin neurons in the periventricular nucleus and in the paraventricular nucleus of the hypothalamus expressed the GH receptor gene transcript. From this observation the authors concluded that GH may act directly on the brain and through a direct action on somatostatin neurons in the hypothalamus i.e., the hormone may participate in the regulation of its own secretion [33]. An additional study showed that the majority of neuropeptide Y (NPY) mRNA-containing cells in the hypothalamic arcuate nucleus expressed the GHR gene transcript, whereas NPY neurons in the dorsomedial hypothalamus did not express the GHR message and this data was considered to confirm that NPY neurons in the arcuate nucleus mediate the feedback effect of $\mathrm{GH}$ on the hypothalamus [34].

By using in situ hybridization histochemistry the distribution of the GHR gene transcript was examined in the 
rat brain and spinal cord. Results from these studies indicated that dense labeling of the hormone receptor could be seen in the arcuate nucleus of the hypothalamus, as reported previously, but also in several other brain areas, including the locus coeruleus, the area postrema, and the commissural part of the nucleus of the solitary tract [35]. Other structures that could labeled with the GHR probe included the superior lateral parabrachial nucleus, the facial, hypoglossal and trigeminal motor nuclei, the nucleus incertus, the dorsal tegmental nucleus, the dorsal raphe nucleus, the nucleus of the trapezoid body, and the superficial layers of the dorsal horn of the spinal cord. All these findings were considered to be indicative of a direct action of $\mathrm{GH}$ on brain regions involved in various aspects of homeostatic control [35]. For instance, the distribution of the GHR message to visceral sensory and motor structures is compatible with a regulatory role of GH in food intake and energy homeostasis. The presence of GHR in the superficial dorsal horn of the spinal cord suggests a role of the hormone in the processing of fine afferent input, and may to some extent explain the beneficial effects seen following $\mathrm{GH}$ replacement in certain chronic pain disorders [36, 37].

\section{STRUCTURE AND CHEMISTRY OF GH RECEPTORS IN THE BRAIN}

Previous studies have demonstrated that the specific binding sites identified for $\mathrm{GH}$ in the various brain regions represent receptor proteins for the hormone $[5,7,10]$. In human brain tissues the molecular sizes of the GH receptor proteins in the various brain regions appeared to differ with regard to binding constants and to the estimated molecular size of the hormone-binding units [5, 25]. For instance, applying cross-linked SDS gel electrophoresis it was found that the GH binding units in hippocampus and the choroid plexus were found to represent proteins with a molecular weight exceeding those identified in the hypothalamus and in the pituitary [5]. Also, when compared the molecular size of the receptor proteins present in the brain with that of the GH receptor in the peripheral liver it was found that the molecular size of the gene transcript predicted from the liver DNA sequence of the hormone was at least two times lower. In the rat a similar situation was observed [6].

Regarding the expression of the gene transcripts of the GHR their structures have been studied and both in the human and the rat they were reported to have great similarities with the corresponding liver entity $[7,13]$. In the rat the entire nucleotide sequence of GHR gene in choroid plexus and spinal cord were $100 \%$ identical with that in the liver $[9,13]$. Also the partially sequenced genes in the hippocampus and hypothalamus were in full agreement with the corresponding parts in the liver receptor gene [38].

Brain regions with high levelsof GHR mRNA-containing cells include the hypothalamus, the thalamus septal region, hippocampus, dentate gyrus and amygdala [33]. A 4.4-kb GHR transcript was found identified in an ovine choroid plexus cell line [39]. In addition, the cloning of a gene encoding the extracellular domain of the GHR in the human choroid plexus has been described [7]. The amino acid sequence predicted from this part of the choroid plexus GHR was reported to be homologous to that of the hormone receptor of the human liver [40]. Furthermore, regarding sex and the expression of the GHR message in the human choroid plexus no difference was observed [7]. The expression of GHR in human brain tissues, both normal and tumoral, as well as in the human glioblastoma cell line U87MG has also been reported [41]. The nucleotide sequence of the GHR gene transcripts identified in the rat hippocampus and spinal cord has been reported [9], as well as those found in the rat choroid plexus and hypothalamus [38].

\section{FUNCTIONAL ASPECTS}

The physiological relevance of the $\mathrm{GH}$ receptors identified in the brain has been the subject for many studies during the past decades. From this research it has become evident that most receptor targets for $\mathrm{GH}$ in the brain seem to be involved in a number of CNS-related behaviors attributed to the hormone. These behaviors include the GH effects on sleep, appetite, cognitive and memory processes as well as neuroprotective effects but also effects on pain processing pathways [7]. Most of these effects of the hormone have been confirmed by studies carried out in vitro, using various types of cells, and by studies in vivo, with a variety of experimental animal models, as well as clinical studies in humans [17, 42-46]. Also, in this context it is essential to consider the well-known age-related reduction in the expression and activity of the GH/IGF-1 axis [10, 47]. This decline seen during the aging process is connected with losses in many functions related to the action of the somatotrophic axis in the whole body but also in the brain [47-51].

\section{Brain GH and Aging}

Indeed, the hypofunction seen in the GH/IGF-1 axis during aging represents a most important example of age-related changes that occur in man. Regarding brain functions this decline in the somatotrophic axis contributes a number of alterations in psychological capabilities seen during aging. Many of these inabilities are included in the spectrum of potential deductions associated with GHD in elderly as well as in adolescents and young adults. The most pronounced disabilities linked to a waning release of $\mathrm{GH}$ and a subsequent decrease in circulating IGF-1 are decreased energy and motivation, decreased motor abilities, impaired cognitive function, sleep deprivation and decreased mood and well-being, i.e. an overall impairment in quality of life [47]. The decline in GH secretion that occurs with increasing age is generally mirrored by a concomitant decrease in plasma levels of IGF-1, the best marker of GH status. Studies have also shown that the decline in the pituitary secretion of $\mathrm{GH}$ in human is accompanied by a concurrent decline in the expression levels of the GHR gene transcript [7] as well as in the density of the GHR protein in the brain $[5,25]$.

\section{GH and Appetite}

Previous studies have indicated that GH has an appetitestimulating effect. It is well documented that patients with GHD increase their food intake during $\mathrm{GH}$ replacement therapies. Furthermore, studies using transgenic mice with 
GH overexpressed in the CNS have demonstrated that it is possible to differentiate the effect of the hormone on body fat mass from that on appetite [47]. It was thus shown that $\mathrm{GH}$ overexpression in the CNS causes hyperphagia-induced obesity in parallel with a central stimulatory effect on appetite and lipolysis. In addition, it was also demonstrated that the GH releasing peptide ghrelin increases food intake [52]. However, it was also shown that the acute effect of ghrelin in this regard is dependent upon a functionally intact GHR signaling [53]. The neuropeptide Y (NPY) is a wellknown for its role in regulation of appetite, and several studies on food intake have confirmed a link between NPY and $\mathrm{GH}[54,55]$. Also, it was earlier found that in the rat hypothalamic arcuate nucleus a $\mathrm{GH}$ secretagogue receptor and NPY are co-localized [56] and studies showing that the GHR gene transcript is expressed in visceral sensory and motor structures in the rat brain suggest a role of $\mathrm{GH}$ in the regulation of food intake and energy homeostasis [35].

\section{GH in Cognition and Memory Function}

During the past decade a potential role of GH and IGF-1 in memory acquisition and cognitive functions has been confirmed in many laboratories. Replacement therapy with GH in adult GHD patients has indicated that both GH and IGF-1 may enhance both long-term and working memory $[11,20,43,57]$. GH replacement during six months in GHD patients was seen to improve both the long-term memory and the working memory [43]. As visualized by functional magnetic resonance imaging this memory improvement was concomitant with a decreased activation in the ventrolateral prefrontal cortex in the brain. However, in spite of all studies indicating beneficial effects of GH on impaired cognitive functions seen in patients with GHD, there are no convincing studies that imply that the hormone would improve cognitive disabilities in elderly healthy non-GHD individuals [58].

Regarding the mechanism underlying the beneficial effects of GH on cognitive functions it is believed that that the hormone induces these effects, at least partly, through its mediator IGF-1. This growth factor is shown to penetrate the $\mathrm{BBB}$ and reach its responsive sites in the CNS [59]. Thus, both GH and IGF-1 may cross the BBB and interact with specific receptors for this hormone in the CNS [28]. As mentioned above, several brain areas, including hippocampus, contain high concentrations of GHR receptors $[7,10]$. In addition, following peripheral administration of GH in rats, the expression of the GHR message is altered in a mode that is compatible with a stimulatory effect on the GHR [8]. Behavioral studies using experimental animals have demonstrated that chronic treatment with GH and IGF1 significantly improves learning and memory in aged rats with impaired GH production [13]. Regarding the mechanism underlying the $\mathrm{GH}$-induced improvements in cognition it is suggested that the hormone GH may exert this beneficial effect by increasing neurogenesis, vascular density and glucose utilization [42]. At the molecular level it is believed that GH may alter the composition of the NMDA receptor subunits in brain areas implicated in learning and memory $[8,13,45,60]$. Using experimental rats, it was shown that GH may influence the NMDA receptor subunits in a mode that is in consonance with improved memory and cognitive capabilities. More recently, a similar effect was demonstrated for IGF-1 [61]. In both in vivo and in vitro studies it have been demonstrated that GH may increase regeneration and prevent apoptosis in hipppocampal cells $[42,62]$.

\section{GH and Neuroprotection}

Evidence that both $\mathrm{GH}$ and IGF-1 may induce neuroprotective effects is well documented in the literature. A number of articles have reviewed this topic and it seems that a growing body of evidence suggests that the somatotrophic axis is integrally involved in the growth and development of the normal CNS but also in the repair of trauma to the brain and spinal cord [63-65]. Several of the neuroprotective effects seen for GH and IGF-1 emerged from their effects on adult cell genesis [42, 48, 66]. For instance, IGF-1 was demonstrated to promote oligodendrocyte recruitment and increase newborn cells with the endothelial phenotype in the hippocampus. This IGF-1induced effects on the endothelial cell phenotype may explain the observed enhancement in the cerebral arteriole density following administration of $\mathrm{GH}$ [66]. These observations stresses the ability of IGF-1 to act as a regenerative agent in the CNS. On the other hand GH, which is less studied in this context, is also suggested to exert similar effects, probably through its ability to release IGF-1.

It has been demonstrated [67] that brain injury in experimental rats may induce the IGF-1 gene transcript within reactive microglia, and that the translation product, the IGF-1 protein, may have a dual role. First, the growth factor may act directly on the stressed cells as a neurotrophic and an antiapoptotic agent. In a second phase, IGF-1 may act as a prohormone for the generation of two active peptides, the tripeptide Gly-Pro-Glu, released from the N-terminal of IGF-1, and the remaining sequence of IGF-1, the des-N-(13) IGF-1. Both these IGF-1 fragments were seen to possess specific neuroprotective properties [67]. This study also revealed that injections $\mathrm{GH}$ into the $\mathrm{CNS}$ at $2 \mathrm{~h}$ subsequent to a hypoxic-ischemic brain injury in juvenile rats gave rise to a significant neuroprotection, which seemed to be different from the neuroprotective effect induced by IGF1[67]. It was also demonstrated that some of the neuroprotective effects of $\mathrm{GH}$ are mediated directly through the GHR without any involvement of IGF-1 [67]. In a more recent study it was suggested that smaller peptide fragments, derived from IGF-1, could have advantages over growth factors in the treatment of brain injury. These fragments could be modified and designed with suitable properties to overcome many of the limitations associated with the native endogenous peptides regarding their potential role as medical drugs [68].

Studies on GH and IGF-1 have shown that both these compounds may reduce the outcome of spinal cord trauma in the rat. For instance, topical application of both hormones was shown to reduce the trauma-induced edema formation and cell damages $[69,70]$. Further studies indicated that GH may improve spinal cord conduction and attenuate edema formation and cell injury in the spinal cord provided 
additional support for a beneficial role of the hormone in injuries to the cord $[8,71]$. In rats exposed to chronic sustained hypoxia injection of $\mathrm{GH}$ increased the hippocampal expression of the IGF-1 gene transcript, reduced the hypoxia-induced hippocampal injury and attenuated hypoxia-induced cognitive deficits [72]. The investigators behind this study concluded that exogenous GH may provide a viable therapeutic intervention to protect hypoxia-vulnerable brain regions from neuronal damage and subsequent deficits in neuro cognitive function. Moreover, injury to the brain and spinal cord in human subjects is shown to decline the circulatory levels of both GH and IGF1 (for a review, see for example [7]). As both GH and IGF-1 are seen to exhibit a wide array of neuroprotective activities, as evidenced in both in vitro studies using various cell systems and in in vivo studies using experimental animal models, it is inviting to speculate upon a possible potential therapeutic utility of both hormones in this context. A study using murine hippcampal cells has shown that GH may counteract opioid-induced cell damage and apoptosis [62] and in a very recent study it has been indicated that the hormone may reverse opioid-induced cognitive impairments also in human (unpublished) emphasizing the importance of the somatotrophic axis in therapeutic strategies for the treatment of various types of drug-induced damages to the brain.

\section{CONCLUSION}

This article summarizes some recent aspects on the characteristics of $\mathrm{GH}$ receptors in the brain. It also emphasize the potential of these receptors as therapeutic targets for the treatment of CNS disorders related to deficits in the GH/IGF-1 axis. In particular it highlights the possibility to use the hormone for the improvement of cognitive functions in patients suffering from impaired production of $\mathrm{GH}$ or from disabilities related to other dysfunctions in the somatotrophic axis. An interesting possibility arises from the observation that the hormone may stimulate regeneration of nerve cells, which open for new therapeutic strategies regarding a variety of disorders resulting from CNS trauma or from brain damages induced by abusing drugs.

\section{CONFLICT OF INTEREST}

The authors confirm that this article content has no conflicts of interest.

\section{ACKNOWLEDGEMENT}

This study was supported by the Swedish Research Council (Grant 9459).

\section{REFERENCES}

[1] Stern WC, Miller, M, Jalowiec JE, Forbes WB, Morgane PJ. Effects of growth hormone on brain biogenic amine levels. Pharmacol Biochem Behav 1975; 3: 1115-8.

[2] Andersson K, Fuxe, K, Eneroth P, et al. Rat growth hormone and hypothalamic catecholamine nerve terminal systems. Evidence for rapid and discrete reductions in dopamine and noradrenaline levels and turnover in the median eminence of the hypophysectomized male rat. Eur J Pharmacol 1983; 95: 271-5.
[3] Donahue CP, Kosik KS, Shors TJ. Growth hormone is produced within the hippocampus where it responds to age, sex, and stress. Proc Natl Acad Sci USA 2006; 103: 6031-6.

[4] Skuse D, Lawrence K, Tang, J. Measuring social-cognitive functions in children with somatotropic axis dysfunction. Horm Res 2005; 64 (Suppl 3): 73-82.

[5] Lai Z, Roos P, Zhai O, et al. Age-related reduction of human growth hormone-binding sites in the human brain. Brain Res 1993; 621: 260-6.

[6] Zhai Q, Lai Z, Roos P, Nyberg F. Characterization of growth hormone binding sites in rat brain. Acta Paediatr Suppl 1994; 406: 92-5.

[7] Nyberg F. Growth hormone in the brain: characteristics of specific brain targets for the hormone and their functional significance. Front Neuroendocrinol 2000; 21: 330-48.

[8] Le Greves M, Steensland P, Le Greves P, Nyberg F. Growth hormone induces age-dependent alteration in the expression of hippocampal growth hormone receptor and N-methyl-D-aspartate receptor subunits gene transcripts in male rats. Proc Natl Acad Sci USA 2002; 99: 7119-23.

[9] Thornwall-Le GM, Zhou Q, Lagerholm S, Huang W, Le Greves P, Nyberg F. Morphine decreases the levels of the gene transcripts of growth hormone receptor and growth hormone binding protein in the male rat hippocampus and spinal cord. Neurosci Lett 2001; 304: 69-72.

[10] Nyberg F. Growth hormone and brain function. In: Ranke MM, Price DA, Reiter EO, Eds. Growth hormone therapy in pediatrics, 20 years of KIGS. Basel: Karger 2007; pp. 450-60.

[11] Deijen JB, de Boer H, Blok GJ, van der Veen EA. Cognitive impairments and mood disturbances in growth hormone deficient men. Psychoneuroendocrinology 1996; 21: 313-22.

[12] Falleti MG, Maruff P, Burman P, Harris A. The effects of growth hormone $(\mathrm{GH})$ deficiency and $\mathrm{GH}$ replacement on cognitive performance in adults: a meta-analysis of the current literature. Psychoneuroendocrinology 2006; 31: 681-91.

[13] Le Greves M, Zhou Q, Berg M, et al. Growth hormone replacement in hypophysectomized rats affects spatial performance and hippocampal levels of NMDA receptor subunit and PSD-95 gene transcript levels. Exp Brain Res 2006; 173: 267-73.

[14] Stabler B. Impact of growth hormone $(\mathrm{GH})$ therapy on quality of life along the lifespan of GH-treated patients. Horm Res 2001; 56 (Suppl 1): 55-8.

[15] Burman P, Broman JE, Hetta J, et al. Quality of life in adults with growth hormone $(\mathrm{GH})$ deficiency: response to treatment with recombinant human $\mathrm{GH}$ in a placebo-controlled 21 -month trial. J Clin Endocrinol Metab 1995; 80: 3585-90.

[16] Johansson JO, Larson G, Andersson M, et al. Treatment of growth hormone-deficient adults with recombinant human growth hormone increases the concentration of growth hormone in the cerebrospinal fluid and affects neurotransmitters. Neuroendocrinology 1995; 61: 57-66.

[17] Nyberg F, Burman P. Growth hormone and its receptors in the central nervous system-location and functional significance. Horm Res 1996; 45: 18-22.

[18] Coculescu M. Blood-brain barrier for human growth hormone and insulin-like growth factor-I, J Pediatr Endocrinol Metab 1999; 12: 113-24.

[19] Burman P, Hetta J, Wide L, Mansson JE, Ekman R, Karlsson FA. Growth hormone treatment affects brain neurotransmitters and thyroxine [see comment]. Clin Endocrinol (Oxf) 1996; 44: 319-24.

[20] Wass JA, Reddy R. Growth hormone and memory. J Endocrinol 2010; 207: 125-6.

[21] Verhelst J, Abs R. Long-term growth hormone replacement therapy in hypopituitary adults. Drugs 2002; 62: 2399-412.

[22] Tanaka H, Kubo T, Yamate T, Ono T, Kanzaki S, Seino Y. Effect of growth hormone therapy in children with achondroplasia: growth pattern, hypothalamic-pituitary function, and genotype. Eur J Endocrinol 1998;138: 275-80.

[23] Ganong WF. Circumventricular organs: definition and role in the regulation of endocrine and autonomic function. Clin Exp Pharmacol Physiol 2000; 27: 422-7.

[24] Walsh RJ, Slaby FJ, Posner BI. A receptor-mediated mechanism for the transport of prolactin from blood to cerebrospinal fluid. Endocrinology 1987; 120: 1846-50. 
[25] Lai ZN, Emtner M, Roos P, Nyberg F. Characterization of putative growth hormone receptors in human choroid plexus. Brain Res 1991;546: 222-6.

[26] Lai Z, Roos P, Olsson Y, Larsson C, Nyberg F. Characterization of prolactin receptors in human choroid plexus. Neuroendocrinology 1992; 56: 225-33.

[27] Ohtsuki S, Takizawa T, Takanaga H, Hori S, Hosoya K, Terasaki T. Localization of organic anion transporting polypeptide 3 (oatp3) in mouse brain parenchymal and capillary endothelial cells. J Neurochem 2004; 90: 743-9.

[28] Pan W, Yu Y, Cain CM, Nyberg F, Couraud PO, Kastin AJ. Permeation of growth hormone across the blood-brain barrier. Endocrinology 2005; 146: 4898-904.

[29] Posner BI, van Houten M, Patel B, Walsh RJ. Characterization of lactogen binding sites in choroid plexus. Exp Brain Res1983; 49: 300-6.

[30] Mustafa A, Adem A, Roos P, Nyberg F. Sex differences in binding of human growth hormone to rat brain. Neurosci Res 1994; 19: 939.

[31] Mustafa A, Nyberg F, Bogdanovic N, Islam A, Roos P, Adem A. Somatogenic and lactogenic binding sites in rat brain and liver: quantitative autoradiographic localization. Neurosci Res 1994; 20 : 257-63.

[32] Lobie PE, Garcia-Aragon J, Lincoln DT, Barnard R, Wilcox JN, Waters MJ. Localization and ontogeny of growth hormone receptor gene expression in the central nervous system. Brain Res Dev Brain Res 1993; 74: 225-33.

[33] Burton KA, Kabigting EB, Clifton DK, Steiner RA. Growth hormone receptor messenger ribonucleic acid distribution in the adult male rat brain and its colocalization in hypothalamic somatostatin neurons. Endocrinology 1992; 131: 958-63.

[34] Kamegai J, Minami S, Sugihara H, Hasegawa O, Higuchi H, Wakabayashi I. Growth hormone receptor gene is expressed in neuropeptide $\mathrm{Y}$ neurons in hypothalamic arcuate nucleus of rats. Endocrinology 1996; 137: 2109-12.

[35] Kastrup Y, Le Greves M, Nyberg F, Blomqvist A. Distribution of growth hormone receptor mRNA in the brain stem and spinal cord of the rat. Neuroscience 2005; 130: 419-25.

[36] Cuatrecasas G. Fibromyalgic syndromes: could growth hormone therapy be beneficial? Pediatr Endocrinol Rev 2009; 6 (Suppl 4): 529-33.

[37] Chopra K, Kuhad A, Arora V. Neoteric pharmacotherapeutic targets in fibromyalgia. Expert Opin Ther Targets 2011; 15: 126781 .

[38] Botros M, Hallberg M, Johansson T, et al. Endomorphin-1 and endomorphin-2 differentially interact with specific binding sites for substance P (SP) aminoterminal SP1-7 in the rat spinal cord. Peptides 2006; 27: 753-59.

[39] Thornwall M, Chhajlani V, Le Greves P, Nyberg F. Detection of growth hormone receptor mRNA in an ovine choroid plexus epithelium cell line. Biochem Biophys Res Commun 1995; 217: 349-53.

[40] Leung DW, Spencer SA, Cachianes G, et al. Growth hormone receptor and serum binding protein: purification, cloning and expression. Nature 1987; 330: 537-43.

[41] Castro JR, Costoya JA, Gallego R, Prieto A, Arce VM, Senaris R. Expression of growth hormone receptor in the human brain. Neurosci Lett 2000; 281: 147-50.

[42] Aberg ND, Brywe KG, Isgaard J. Aspects of growth hormone and insulin-like growth factor-I related to neuroprotection, regeneration, and functional plasticity in the adult brain. Scientific World J 2006; 6: 53-80.

[43] Arwert LI, Veltman DJ, Deijen JB, van Dam PS, Drent ML. Effects of growth hormone substitution therapy on cognitive functioning in growth hormone deficient patients: a functional MRI study. Neuroendocrinology 2006; 83: 12-9.

[44] Savine R, Sonksen P. Growth hormone - hormone replacement for the somatopause?. Horm Res 2000; 53 (Suppl 3): 37-41.

[45] Sonntag WE, Ramsey M, Carter CS. Growth hormone and insulinlike growth factor-1 (IGF-1) and their influence on cognitive aging. Ageing Res Rev 2005; 4: 195-212.

[46] Svensson J, Johannsson G, Bengtsson BA. Body composition and quality of life as markers of the efficacy of growth hormone replacement therapy in adults. Horm Res 2001; 55 (Suppl 2): 5560 .
[47] Giordano R, Lanfranco F, Bo, M. et al. Somatopause reflects agerelated changes in the neural control of GH/IGF-I axis. J Endocrinol Invest 2005; 28: 94-8.

[48] Aberg D. Role of the growth hormone/insulin-like growth factor 1 axis in neurogenesis. Endocr Dev 2010; 17: 63-76.

[49] Fanciulli G, Delitala A, Delitala G. Growth hormone, menopause and ageing: no definite evidence for 'rejuvenation' with growth hormone. Hum Reprod Update 2009; 15: 341-58.

[50] Sherlock M, Toogood AA. Aging and the growth hormone/insulin like growth factor-I axis. Pituitary 2007; 10: 189-203.

[51] Gasperi M, Castellano, AE. Growth hormone/insulin-like growth factor I axis in neurodegenerative diseases. J Endocrinol Invest 2010; 33: 587-91.

[52] Lim CT, Kola B, Korbonits M, Grossman AB. Ghrelin's role as a major regulator of appetite and its other functions in neuroendocrinology. Prog Brain Res 2010;182: 189-205.

[53] Egecioglu E, Bjursell M, Ljungberg A, et al. Growth hormone receptor deficiency results in blunted ghrelin feeding response, obesity, and hypolipidemia in mice. Am J Physiol 2006; 290: E317-25.

[54] Dimaraki EV, Jaffe CA. Role of endogenous ghrelin in growth hormone secretion, appetite regulation and metabolism. Rev Endocr Metab Disord 2006; 7: 237-49.

[55] Konturek SJ, Konturek JW, Pawlik T, Brzozowski T. Brain-gut axis and its role in the control of food intake. J Physiol Pharmacol 2004; 55: 137-54.

[56] Willesen MG, Kristensen P, Romer J. Co-localization of growth hormone secretagogue receptor and NPY mRNA in the arcuate nucleus of the rat. Neuroendocrinology 1999; 70: 306-16.

[57] Popovic V. GH deficiency as the most common pituitary defect after TBI: clinical implications. Pituitary 2005; 8: 239-43.

[58] Arwert LI, Veltman DJ, Deijen JB, van Dam PS, Delemarre-van deWaal HA, Drent ML. Growth hormone deficiency and memory functioning in adults visualized by functional magnetic resonance imaging. Neuroendocrinology 2005; 82: 32-40.

[59] Pan W, Kastin AJ. Interactions of IGF-1 with the blood-brain barrier in vivo and in situ. Neuroendocrinology 2000; 72: 171-8.

[60] Sonntag WE, Bennett SA, Khan AS, et al. Age and insulin-like growth factor-1 modulate N-methyl-D-aspartate receptor subtype expression in rats. Brain Res Bull 2000; 51: 331-8.

[61] Le Greves M, Le Greves P, Nyberg F. Age-related effects of IGF-1 on the NMDA-, GH- and IGF-1-receptor mRNA transcripts in the rat hippocampus. Brain Res Bull 2005; 65: 369-74.

[62] Svensson AL, Bucht N, Hallberg M, Nyberg F. Reversal of opiateinduced apoptosis by human recombinant growth hormone in murine foetus primary hippocampal neuronal cell cultures. Proc Natl Acad Sci USA 2008; 105: 7304-8.

[63] Torres Aleman I. Role of insulin-like growth factors in neuronal plasticity and neuroprotection. Adv Exp Med Biol 2005; 567: 24358.

[64] Harvey S, Baudet ML, Sanders EJ. Growth hormone-induced neuroprotection in the neural retina during chick embryogenesis. Ann N Y Acad Sci 2009; 1163: 414-6.

[65] Nyberg F. The role of the somatotrophic axis in neuroprotection and neuroregeneration of the addictive brain. Int Rev Neurobiol 2009; 88: 399-427.

[66] Anderson MF, Aberg MA, Nilsson M, Eriksson PS. Insulin-like growth factor-I and neurogenesis in the adult mammalian brain. Brain Res Dev Brain Res 2002; 134: 115-22.

[67] Scheepens A, Williams CE, Breier BH, Guan J, Gluckman PD. A role for the somatotropic axis in neural development, injury and disease. J Pediatr Endocrinol Metab 2000; 13 (Suppl 6): 1483-91.

[68] Guan J, Gluckman PD. IGF-1 derived small neuropeptides and analogues: a novel strategy for the development of pharmaceuticals for neurological conditions. Br J Pharmacol 2009; 157: 881-91.

[69] Nyberg F, Sharma HS. Repeated topical application of growth hormone attenuates blood-spinal cord barrier permeability and edema formation following spinal cord injury: an experimental study in the rat using Evans blue, ([125])I-sodium and lanthanum tracers. Amino Acids 2002; 23: 231-9.

[70] Sharma HS, Nyberg F, Westman J, Alm P, Gordh T, Lindholm D. Brain derived neurotrophic factor and insulin like growth factor-1 attenuate upregulation of nitric oxide synthase and cell injury following trauma to the spinal cord. An immunohistochemical study in the rat. Amino Acids 1998; 14: 121-9. 
[71] Winkler T, Sharma HS, Stalberg E, Badgaiyan RD, Westman J, Nyberg F. Growth hormone attenuates alterations in spinal cord evoked potentials and cell injury following trauma to the rat spinal cord. An experimental study using topical application of rat growth hormone. Amino Acids 2000; 19: 363-71.

[72] Li RC, Guo SZ, Raccurt M, Moudilou E, Morel G, Brittian KR, Gozal D. Exogenous growth hormone attenuates cognitive deficits induced by intermittent hypoxia in rats. Neuroscience 2011; 196 : 237-50.

[73] Enhamre E, Carlsson A, Grönbladh A, Watanabe H, Hallberg M, Nyberg F. The expression of growth hormone receptor gene transcript in the prefrontal cortex is affected in male mice with diabetes-induced learning impairments. Neurosci Lett 2012; 523: 82-6.

(c) Hallberg and Nyberg; Licensee Bentham Open.

This is an open access article licensed under the terms of the Creative Commons Attribution Non-Commercial License (http://creativecommons.org/licenses/by$\mathrm{nc} / 3.0 /$ ) which permits unrestricted, non-commercial use, distribution and reproduction in any medium, provided the work is properly cited. 